\title{
EMBRACING ASEAN COMMUNITY: MALAYSIA, INDONESIA AND BRUNEI YOUTH PERSPECTIVE
}

\author{
Nurul Huda Marwan \\ Faculty of Social Sciences, Universiti Malaysia Sarawak, \\ Kota Samarahan, , Malaysia \\ Ahmad Nizar Ya'akub \\ Faculty of Social Sciences, Universiti Malaysia Sarawak, \\ Kota Samarahan, , Malaysia \\ Noor'ain Aini, \\ Faculty of Social Sciences, Universiti Malaysia Sarawak, \\ Kota Samarahan, , Malaysia
}

*Corresponding author

Email address: hmnurul@unimas.my

\begin{abstract}
After 48 years in existence, ASEAN has eventually transformed from periodic annual meetings of ministers to setting ambitious goals to transform itself into an integrated region; the ASEAN Community by the year 2020. An important tension in this transformation is the question of whether the people of ASEAN are aware and ready to embrace the initiative. As such, this study is interested to discover youths' awareness, attitudes and expectations toward the establishment. For this purpose, a set of questionnaires has been distributed to a total of 600 university students from Universiti Malaysia Sarawak, Universiti Brunei Darussalam and Universitas Tanjungpura, Kalimantan which act as the aggregate view of youths originating from Borneo. The finding reveals limited familiarity on ASEAN and ASEAN Community among the respondents. Hence, this study implies that a concerted effort should be done in communicating the message of ASEAN Community to the ASEAN masses. Core elements include sufficient exposure on ASEAN Community's vision and mission, availability of specific mandatory courses on both school and university level and the initiation of more intra-ASEAN exchange programs; strengthening friendships and ensuring eventual steps to a greater consolidated integration. Future expansions to this study could be applied in other universities across the region in order to better gauge the general awareness and readiness of the youth towards the initiative.
\end{abstract}

Keywords: ASEAN, ASEAN Community, Southeast Asia, integration, Borneo, youth, awareness, readiness 


\section{INTRODUCTION}

This paper argues that the aspiration of ASEAN Community announced by ASEAN leaders in 2008 to unite and integrate the region into a single community requires active participation and commitment of the ASEAN people to further consolidate ASEAN integration. Since ASEAN Community's mission is aimed for the benefit of everyone in the region, it is naturally imperative to involve everyone in its realization, particularly in its crucial stages of its formation process. Kulasari (2011) stated that the formation of ASEAN community have increased the focus on people-centered organizations and stirring away from a pure state-centered organizations approach. As supported by Kamal (2009), people-centered approach for the eventual goal of ASEAN Community is one of the major challenges to the ongoing integration activities and agreements; these initiatives must ensure eventual benefits to the people of ASEAN. With a population of 633 million people, ASEAN is considered to be one of the most diverse regions globally. ASEAN member states are very unique as it is diverse in culture, religion and language. ASEAN leaders have set the goals to form an ASEAN Community by the year 2020 to ensure everyone a better standard of living in the region. The initiative experienced a fast-tracked execution five years earlier than the planned year through the signing of the Cebu Declaration on the Acceleration of the Establishment of an ASEAN Community in 2015 .

Youth of today especially those educated in tertiary educational institutes are the future leaders and the generation that will continue the mission of ensuring the success of ASEAN integration through the concept of ASEAN Community. Thus, their attitudes, awareness and expectations towards ASEAN Community need to be carefully explored. Focusing on the Borneo Island region, the sample pool of university students in this study is drawn from three major institutions: Universiti Malaysia Sarawak, Universiti Brunei Darussalam and Universitas Tanjungpura, Kalimantan. As evidenced in the ASEAN Foundation (2007), it was decided among the leaders during the 12th ASEAN leaders Summit Meeting that they encourage the increased involvement of ASEAN youth at the national and regional level activities. In addition, it is an imperative that ASEAN member nations need to promote greater institutional collaboration in promoting ASEAN awareness among this generation in order to ensure that they can make valuable and lasting contributions in the process of making ASEAN Community a success. This particular study aims to act as a reference for legal practitioners and policy makers of Malaysia, Indonesia and Brunei to aid them in the process of policymaking and formulating considerations based on realistic status quo, from the perspective of the awareness and readiness of Borneo youths. It is hoped that this publication would be useful to the governments of ASEAN as it is imperative to be acquainted with citizens' thought processes. It is evident that public participation is one of the most important elements to be considered in formulating and executing national and regional plans.

\section{ASEAN COMMUNITY}

There is a great amount of research conducted on the subject of ASEAN Community and available literature, yet there are few studies in the context of Borneo. Most available literature on ASEAN Community focuses on the issues and challenges that have been addressed or need to be overcome by ASEAN members to achieve their target. It is undeniable that the issues and challenges are crucial to be highlighted in the study of ASEAN Community. However, sole focus on this perspective may overlook the rest of the underlying issues and their potential impacts in the process of achieving ASEAN Community. For instance, sole focus on existing issues and challenges only examines the superficial problems detected by leaders and policymakers. It is important to stress that the launch of ASEAN Community in 2015 does not only benefit ASEAN leaders and the region's upper class, but it is a region-wide inclusive initiative particularly at the grassroots level. In addition, the success of ASEAN Community is not only dependent on the government alone, but also relies on the commitment of the ASEAN people. 
To gain more understanding on ASEAN Community, it is important to know the factors that contributed to the birth of it. The leaders of ASEAN were committed to form ASEAN Community in 2003 during the $9^{\text {th }}$ ASEAN Summit with the expectations to realize the goal of one vision, one identity, and one community by the year 2020. It aims to develop a place where all ten member countries come together to build a better place to live for everyone. In theory, the initiative is composed of three main pillars; the ASEAN Political-Security Community, the ASEAN Socio-Cultural Community and the ASEAN Economic Community; each pillar has its own specific blueprint.

The concept of a community of ASEAN was conceived from the proposal for an ASEAN Economic Community suggested by Goh Chok Tong, the then Prime Minister of Singapore. The aspiration had been proposed to be the next step in the regional economic integration by the then Prime Minister Goh in November 2002 at the ASEAN Summit in Phnom Penh (Severino, 2006). Most ASEAN leaders during that time including the then President were very anxious over the reduced capability of ASEAN countries to attract foreign direct investments due to negative investor perceptions on Southeast Asia's economic prospects especially after the incident of Asian Financial Crisis in 1997. Hence, recognizing the need for a regional economic integration, ASEAN leaders at that time tried to find a way to convince investors from both inside and outside that when the region's economy is integrated, it has very good future prospects as ASEAN's market is equivalent to almost half of China's population in numbers. Therefore, the formation of an ASEAN Economic Community is a good platform in attracting new investors to do their business in the region to ensure sustainable economic development by all parties.

The declaration that has been made in Bali Concord II in 2003 was to pave the way for ASEAN to begin a concerted initiative to forge regional integration with the end goal of an integrated regional community by the year 2020. In a way, they are actually saying that ASEAN aims to form an ASEAN Community because of the need to form a regional community. Lenz (2011) also supported the aforementioned fact by stating that there are several regional institutions including ASEAN that have stated their goal to imitate regional community building model, and in the ASEAN context is by targeting to establish ASEAN Community in 2015.

In addition, Termsak (2009) states there are a few driving force to build an ASEAN Community. Firstly is for the sake of the comprehensive security where there is a need to strengthen political cooperation in ensuring peace and security in the region. Secondly is to increase economic competitiveness of ASEAN as a production base and a regional market for international economic competition. Lastly is to promote ASEAN solidarity and identity in order to gain support for ASEAN's community building efforts as well as international acknowledgment. Therefore, it is clear that there are several factors that lead to the establishment of an ASEAN Community. The idea for an ASEAN Community is not only based on one perspective, but from multilateral vantage points. From the security perspective, ASEAN was formed to counter the spread of communism and to ease territorial disputes in the region. That concern does not end only at that point with the birth of ASEAN but it continues until integration goals of ASEAN Community are achieved. Meanwhile the economic perspective also attracts crucial attention in the development of creating a regional community. As mentioned earlier by Severino (2006), ASEAN Community is actually an expression of the desire to create a unified ASEAN economic in which is the first major step for regional integration and this has been supported by Termsak (2009) by stating that one of the driving factors to create an ASEAN Community is to enhance economic competitiveness so that ASEAN could stand strong in the global economic environment. Cuyvers (2007) added that the aims and purposes of an ASEAN Community as;

"were on the one hand to bring about cooperation in the economic, social, cultural, technical, educational and other fields, and on the other hand, in the promotion of regional peace and stability through abiding respect for justice and the rule of law and adherence to the principles of the United Nations Charter". 
Thus, from the few mentioned statements above, it is clear that the concept of ASEAN Community will offer a lot of benefits to the member countries and ASEAN people would be able to competently compete with others when it is successfully achieved in few more years. However, the formulation of the ASEAN Community has been condemned for being too elitist and missing serious efforts to implore public participation and opinion. As mentioned by Moorthy and Benny (2012) that the conception of 'community' in ASEAN lacks the essential components of achievement in other regional community such as in the European Community(constituting one of the three pillars of the European Union) which is mainly based on the participation of the grassroots. This is because the people have always been seen as one of the significant components in the development of regional integration. Termsak (2009) shared the same perspective that in order to make community building efforts in ASEAN as a success, ASEAN needs active support from all levels of the population.

\section{PERCEPTION}

According to Cherry (2013), perception in general focuses on the usage of five senses; touch, sight, taste, smell and hearing plus cognitive processes to process and interpret information. The process of interpreting information is supposed to be continual and progressive. Due to the fact that there is no specific apparatus universally agreed upon to quantify perception in the discipline of social sciences, it would be noteworthy to define this based on the tri-relations of perception-recognition-action. Precisely, for the purposes of this research, perception in the context of respondents' reaction will be determined by gauging their attitudes and level of awareness towards the formation of ASEAN Community. The questions implied are related to respondents' personal preferences and feelings. By looking at those elements, this will assist in determining whether respondents positively or negatively accept the proposed implementations. This practice is very crucial because in participative development, individuals who technically involved in the particular projects should have the major say and their opinions and responses are very crucial to be considered.

Perception is usually assessed by clinical studies and experiment to determine the accuracy of the response towards stimulus (Troscianko and Smith, 2010). However, in social sciences, the study of perception creation is not the main field of study but the effects of human perception are very important in order to study how perception influences attitudes and behavior of the masses. Among the factors that influence perception is based on each individual's proficiency and understanding on certain issues. Even though it is not necessary for someone to possess expertise in any particular issue before the individual perception is neurologically formed, prior knowledge about significant events is important as humans has the ability to connect previously available related information before coming up with their personal conclusions. Prior knowledge helps the individual to be more critical in analyzing any new information and interpreting data. The output from the thinking process is defined as perception and individual responses towards it lead to the varying human attitudes and behavior towards external stimuli.

Experience plays a huge role in generating impression towards any particular issue in the process of perception formation. Experience is defined as a mental phenomena that individuals personally lived through or encountered, knowledge or practical wisdom gained as one had undergone, or things that one generally observes, encounters or undergoes over the course of time (Free Online Dictionary, 2013). Bad experiences left bad perception in the individual and vice versa. In conducting the research on awareness and perception of any particular group, chosen respondents must possess sufficient_prior experiences of the studied event. This idea is significant with the focal point of participative development. Being involved directly will create a more realistic point of view and respondents who are locally involved are believed to be more effective in identifying and addressing real-time issues. Besides that, respondents' direct involvement in any events has an intrinsic importance of self-determination whereby respondents are capable to pose and address any particular issue that outsiders would never be able to effectively comprehend in a short time. 


\section{DATA COLLECTION}

To obtain relevant and statistically significant data, a quota-sampling technique is utilized to ensure samples are balanced by gender and by the subject of study. A sample of 200 students is selected for the survey conducted in three prominent Borneo universities, namely Universiti Malaysia Sarawak, Universiti Brunei Darussalam and Universitas Tanjungpura, Kalimantan. All respondents are from school of humanities and social sciences. The respondents are also evenly and reasonably spread over several years from first to third year students (or including fourth years). A slight, unintended over-sampling of first and second year student's is done among Brunei student population due to third year students being away from Brunei participating in overseas student exchange programs for a whole year. Respondents are asked a series of questions in order to assess their knowledge about ASEAN and ASEAN Community via questionnaire format. The main questions primarily consist of asking basic knowledge on ASEAN; the year of ASEAN's establishment, the names of ASEAN countries, the geographical location of ASEAN countries, sources in gaining information about ASEAN.

With reference to the goal of gauging respondents' awareness on ASEAN Community, respondents are asked whether they have heard about it, when will it be established and their opinion on the importance of many aspects of cooperation and integration among ASEAN member states. The questionnaire then asked for respondents' opinion on whether they feel that they are a citizen of ASEAN, whether does it make any difference in their lives if ASEAN did not exist and; whether they are interested to know more about other countries in ASEAN. These questions are asked to understand their attitude towards ASEAN Community. Finally, regarding respondents' expectations towards ASEAN Community, respondents' are required to state their readiness towards the initiative by answering questions such as; are they optimistic about the success of it, are they ready to experience free flow of labor in the Southeast Asian region, are they ready to compete with graduates from other ASEAN countries for jobs, and are they ready to share economic development of their country with other less-developed ASEAN member states.

\section{RESULTS AND DISCUSSION}

\section{(i) Knowledge and Awareness of ASEAN and ASEAN Community}

The majority of respondents are able to correctly identify ASEAN member states, still the numbers are comparatively few; $15 \%$ counted in non-member countries such as South Korea, China, India and Taiwan. Indonesia, Malaysia, Brunei, Singapore, the Philippines and Thailand are easily listed; however, Myanmar, Cambodia, Laos and Vietnam tend to be overlooked by the respondents. The respondents are asked to identify the ASEAN countries geographically on the map provided; results indicate that all respondents know where their home country is located. The majority of respondents in each country are able to partially answer correctly the locations of all ASEAN member states. Although most of respondents correctly identify the location of their own country as well as Singapore, few managed to correctly locate Laos. Nevertheless, Myanmar, Cambodia, Laos and Vietnam are the least identifiable.

In regards to the sources of information, the majority of respondents indicate that their main sources are primarily Internet (81.5\% for Malaysians, $71.6 \%$ for Bruneians, and $71.4 \%$ for Indonesians) while about $65.1 \%$ chose television as their major source of information. To compare with the research done by Thompson and Thianthai (2007), it is notifies that the function of television in introducing ASEAN to the people is dramatically decreased. In their findings, almost $90 \%$ of respondents gained information about ASEAN from television. However in 2013, the number has decreased to almost $34 \%$. This occurrence might be affected either by the decrease number of people watching television or decrease number in the news of ASEAN being broadcast in national television. Meanwhile, radio and friends are listed as a secondary source and the least important sources are books and travelling. These observations indicate that young people prefers new media to acquire latest information about ASEAN and ASEAN Community that is 
virtually reachable on any digital device. The usual examples of new media comprise of websites such as social media, wikis, blogs and online newspapers.

Respondent were further asked on their familiarity towards ASEAN. As mentioned by Baumeister and Leary (1995), sense of belonging started from the process of familiarizing oneself towards the group itself. Based on this idea, it is crucial for the citizens to be familiarized with the idea of ASEAN first before they are introduced into further initiative such as ASEAN Community. Once they are familiar of the idea, they will start to feel that they are belonging to that group and their productivity will increase. Only a small minority of $8.8 \%$ Bruneian respondents who are 'very familiar' with ASEAN, while $6.5 \%$ and $6.6 \%$ for both Malaysian and Indonesian respondents. The majority answered 'somewhat familiar' and less than 1\% for each country who are 'not familiar with ASEAN'. This suggests that Borneo university youth lacks awareness on the existence of ASEAN. Meanwhile, a majority of respondents for each country identified 1967 as the year of ASEAN was founded; other responses stretched from 1947 to 1977. Malaysian students exhibit a stronger familiarity with ASEAN as $40.1 \%$ answered the question correctly, followed by Brunei $30.3 \%$, and Indonesia $29.6 \%$.

In regards to ASEAN Community, more than $70 \%$ of respondents from each country have heard about the initiative; Malaysian respondents led with $87 \%$, followed by Indonesians with $75.3 \%$ and Bruneians $72.2 \%$. The respondents were also requested to identify the year of establishment of ASEAN Community, in which they need to choose either the year of 2015, 2017 or 2020 . Figure 1 shows that 50.9\% of total respondents in Brunei identify that ASEAN Community will be established in 2020, while 45.2\% of Malaysian and 34.4\% of Indonesian respondents shared the same answer. As mentioned earlier that in the $9^{\text {th }}$ ASEAN Summit, the plans of ASEAN Community has pushed the establishment from the year 2020 to 2015. In addition, $57.8 \%$ of Indonesian respondents correctly stated 2015 as the year of ASEAN Community coming to operation, with Malaysians at $42 \%$ and Bruneians at $42.4 \%$. These figures suggest that Borneo university students are generally aware with the formation of ASEAN Community.

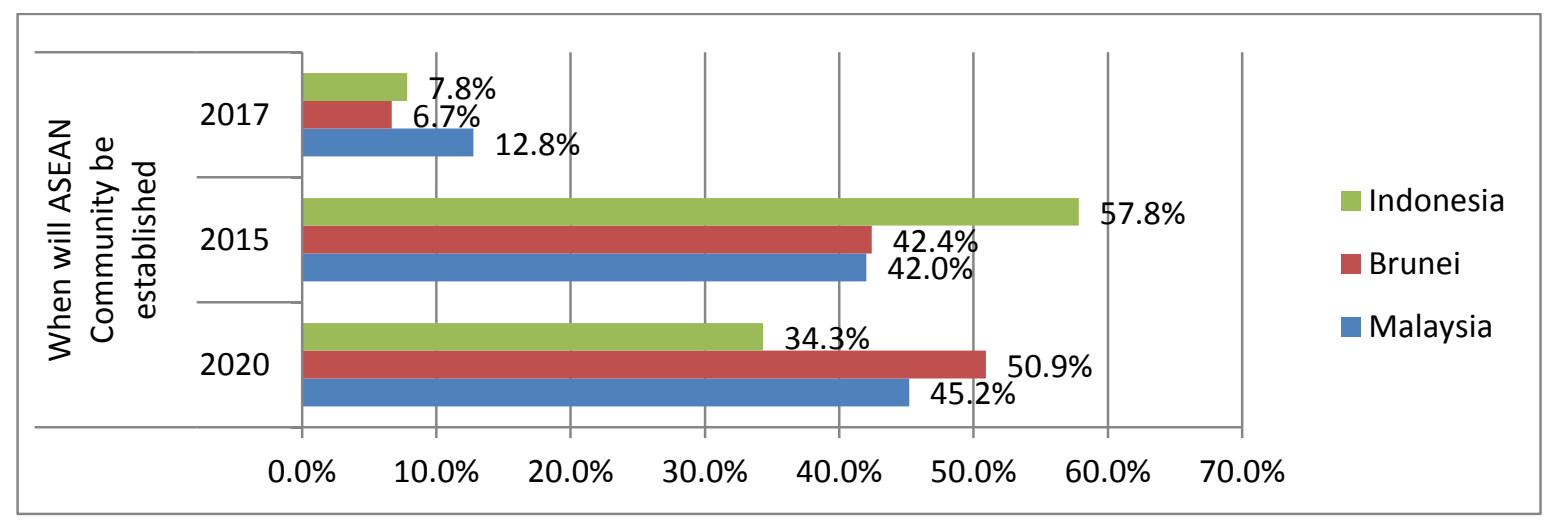

Fig. 1: Respondents' Awareness on the Establishment of ASEAN Community

\section{(ii) Attitudes toward ASEAN and ASEAN Community}

Respondents are asked whether they identify themselves as a citizen of ASEAN in order to understand their attitudes toward ASEAN. About $94.4 \%$ of Indonesian respondents strongly agree and somewhat agree that they belong to ASEAN, followed by Malaysia with $93.5 \%$ and Brunei $85.8 \%$. Less than $5 \%$ of respondents strongly disagree with the statement. In the discussion of whether the respondent is ready for ASEAN 
Community, Malaysian and Bruneian respondents seem to be unsure whereby $50 \%$ of them answering 'maybe'. The majority of Indonesian respondents indicate that they are ready for the commencement of ASEAN Community in 2015: 61.3\% stating 'yes' (Figure 2):

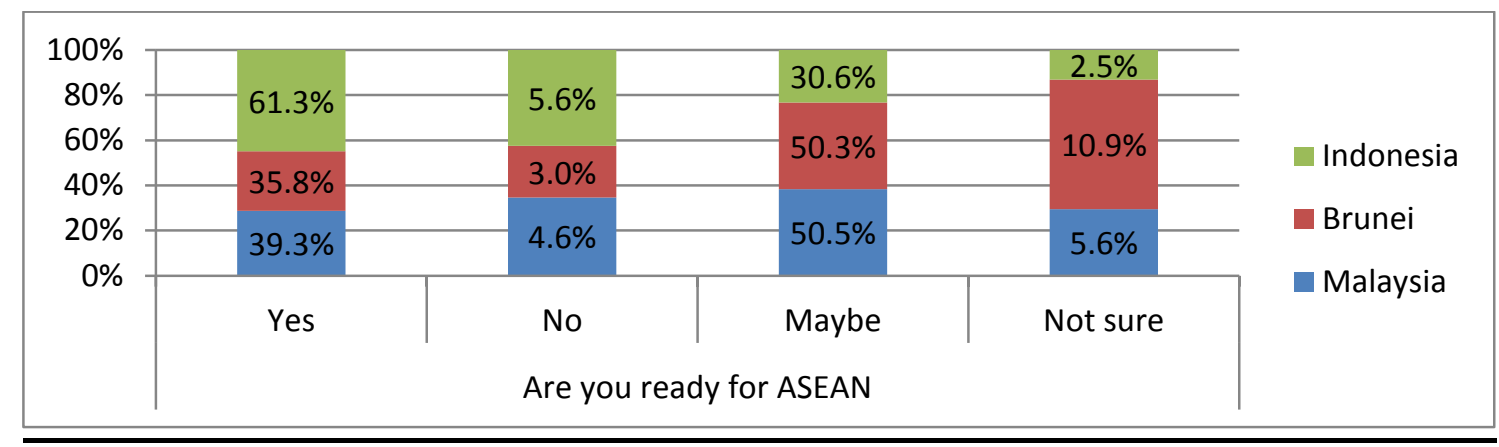

Fig. 2: Respondents' Readiness for ASEAN Community

Respondents are further inquired whether they are optimistic about the success of ASEAN Community. Likewise, a majority of Indonesian respondents who are ready with the initiative are those who are really optimistic with its success $(58.3 \%)$. Meanwhile only $16.7 \%$ of total respondents felt that the establishment of ASEAN Community will not succeed. There are several factors that influenced their answer; the prominent factor is the idea that the ASEAN Community itself is not realistically acceptable by ASEAN people. This is reflected with the question of whether the initiative is accepted by the people of ASEAN where $68.9 \%$ of Malaysian and $69.9 \%$ of Bruneian respondents answered 'no', 'maybe' and 'not sure'. The majority of Indonesian respondents opined that people of ASEAN accepted the initiative, with $50.5 \%$ of them answered 'yes' to the question. To contrast, the consensus is generally positive to ASEAN Community: the majority of the respondents from each country indicated that the creation of ASEAN Community is good for ASEAN countries as a whole.

\section{(iii) Expectations toward ASEAN Community}

Final substantive findings of the survey relate to students' expectations toward ASEAN Community. In the discussion of whether respondents are ready to experience free flow of labor in the Southeast Asian region, it basically focuses on one of the plans in the ASEAN Economic Community. This is due to the significance that they are expected to enter the job market after graduation. $40 \%$ of Indonesian respondents answered 'yes' and the rest answered either 'no', 'maybe' and 'not sure'. 23.5\% of Malaysian respondents answered 'yes' to the same question. A similar pattern is observed in Bruneian respondents whereby only 36.1\% indicate that they are ready for free flow of labor in the region. This observation somehow suggests that Borneo youth are still not ready to experience gradual movement of labor in the region. However as a reassurance, CIMB ASEAN Research Institute in late 2013 announced that the ASEAN Economic Community will not open national borders for free flow of labor in 2015; only one program will be implemented to ensure easy access and mobility for skilled labors in eight major professions (Jones, 2015).

Respondents were further asked whether they are ready to compete with graduates from other ASEAN countries to get job. As expected, $66.1 \%$ of Indonesian respondents considered 'yes' that they are ready to compete with other graduates from other ASEAN member states, while only $9.4 \%$ indicated that they are not ready for it. Malaysian respondents' who opted to state they are ready stands at $41.3 \%$ and $35.5 \%$ for Bruneian respondents. This indicates that even though a large number of respondents are not 
ready to experience free flow of labor in Southeast Asia, data suggests that they are ready in experiencing positive employment market competition. Furthermore, the idea of sharing economic development among ASEAN countries is asked in order to gauge respondents' willingness to share their countries' economic advantages with other people in the region. Observations indicate that Indonesian and Malaysian respondents are willing to share their economic development with the rest of ASEAN member states (each stands at 51.6\% and 43.9\%), however this not necessarily in the case of Bruneian respondents. This suggests that Bruneian students still find the idea of sharing economic development is something that they are not ready yet with a majority answering 'no', 'maybe' and 'not sure' to the question.

The respondents were also asked whether the creation of ASEAN Community would benefit them as individuals. The majority of respondents (Figure 3) in each country believed that they would benefit from the initiative. Less than $14 \%$ of respondents opined that the aspiration is not going to be beneficial to them as an individual. In total, the percentage of respondents that answered 'maybe' and 'not sure' stands at $46.9 \%$ for Malaysians, $45.7 \%$ for Bruneians and 50.8\% for Indonesians. In all, the data suggests that students can be considered partially ready to embrace ASEAN Community; a large percentage opined that they are not yet ready to be affected by the sudden changes that would be brought by the initiative.

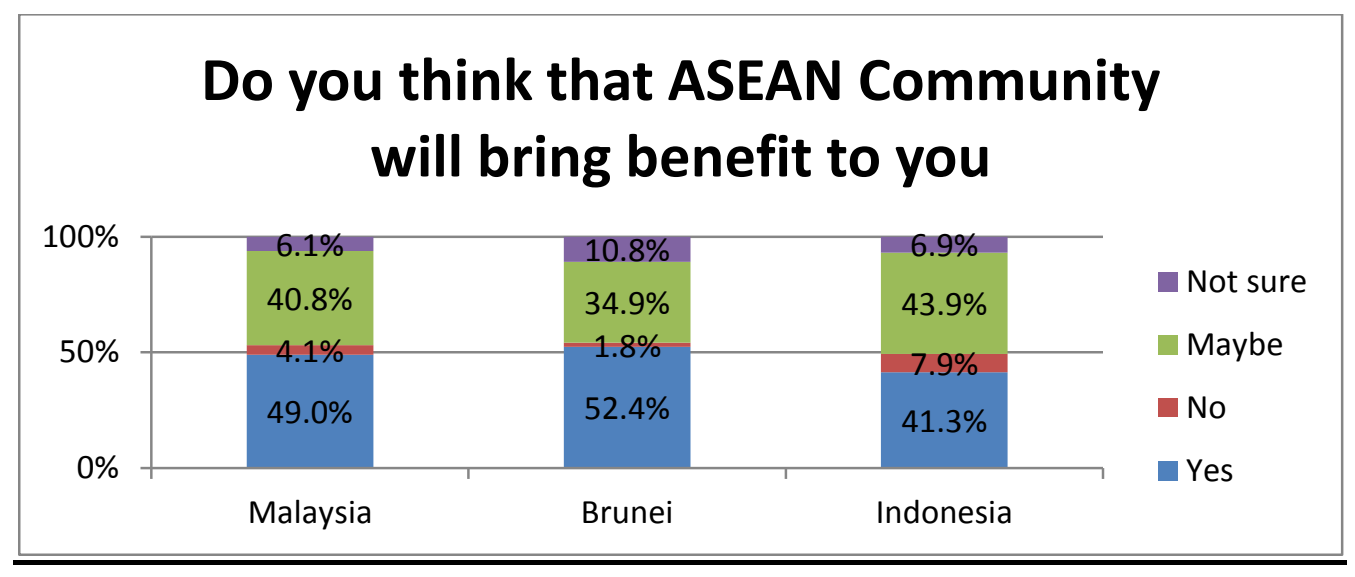

Fig. 3: Respondents' Expectation on the Benefits of ASEAN Community

\section{CONCLUSION AND RECOMMENDATION}

The general attitudes of respondents toward the proposed implementation of ASEAN Community are positively inclined. A majority of respondents in each country consider that the initiative is beneficial to themselves as individuals as well as to their country. In several instances Malaysian and Bruneian respondents share the same general undecided notion while Indonesian respondents generally appear to be more positive and optimistic. As to the respondents' expectations, the majority of Borneo university students are still not ready to experience free flow of labor in the region, although they generally consider themselves to be ready to compete with other graduates from other ASEAN member states in obtaining jobs.

Certainly, the lack of ASEAN and ASEAN Community awareness is a major obstacle toward fulfilling the vision of ASEAN Community 2015. Even though a majority of respondents have heard about ASEAN Community, but the general notion is seemingly pessimistic towards the success of its establishment. This is due to the lack of information and understanding among them on the whole purpose of the integration. Hence, promoting ASEAN and ASEAN Community is a collective responsibility among ASEAN governments in ensuring its success. In the context of Malaysia, the Ministry of Foreign Affairs, Tourism 
and Culture as well as International Trade and Industry are among the main agencies that are responsible in promoting greater awareness of ASEAN and ASEAN Community among the Malaysian youth and citizens. These agencies need to embark on a very aggressive campaign to further foster the collective ASEAN spirit in Malaysia since the findings of the study shows that the familiarity on ASEAN and ASEAN Community is limited. As such, the most appropriate medium for promoting ASEAN Community is via mass media, specifically through the internet and television.

A final suggestion is that a specific course on ASEAN Community should be introduced in school and academic institutions in Malaysia, Indonesia and Brunei as a platform to introduce ASEAN and ASEAN Community to the students. Apart from that, it is highly suggested that several programs be introduced and improved particularly intra-ASEAN youth exchange programs and educational trips visiting towns and historical places around the Southeast Asian region to strengthen friendship and to inculcate in-depth understanding among youths. It is important to stress again the fact that these youngsters today are future ASEAN leaders; thus positive intra-regional exposure would lead to eventual culture of being a part of ASEAN and ASEAN Community.

However, mere policy alterations and renewals must be firmly backed with substantial financing to encourage more youth participation in ASEAN's community-building initiatives. From the Malaysian perspective, there exist sufficient financial incentives such as scholarships and study grants for students to perform well in their respective fields of study and subsequently contributing to the Malaysian economy. It could also be argued that academic cooperation between ASEAN's universities has been done before. However there is a lack of a single unified regional scholarship initiative that is focused on undergraduates, in which this study is focused. This concept mirrors EU's Erasmus initiative and could be further explored in the future with ASEAN's unique mold. This in theory could drive intra-regional academic cooperation to new levels as it is focused on undergraduates rather than postgraduate students; the frequency of students working towards their first degree participating in academic exchanges could be increased and this could slowly build a critical mass of regionally integrated future leaders.

In a nutshell, ASEAN Community is not impossible to be put into force by 2020. It will indeed be a remarkable moment and indicator for ASEAN to be a powerful regional institution in the world. Instead of making this vision as an exclusive target of elitists, ASEAN countries should encourage the participation of the grassroots as effective utilization of human resources in fulfilling the region's need. It is difficult to expect a sense of unified ASEAN identity to emerge unless the people primarily drive the efforts ASEAN integration, or at least ASEAN governments prioritize the people as the core of regional-building activities. Failure to address the roles of people in either national or regional agenda will eventually lead to the failure of agenda. In all, the initiative of ASEAN Community is truly an important plan conceived by the people ASEAN. Despite multitudes of problems faced by each ASEAN member states, unity of the people can help turn the aspiration into a reality.

\section{ACKNOWLEDGEMENT}

This research was supported by Research Acculturation Grant Scheme RAGS/SS/04(1)/903/2012(04) from Ministry of Higher Education, Malaysia.

\section{REFERENCES}

Asia Foundation (2007), Promoting ASEAN among the Youth. Retrieved from www.aseanfoundation.org 
Baumeister, R.F \& Leary, M.R. (1995), The Need to Belong: Desire for Interpersonal Attachment. Psychological Bulletin, 117(3), 497-529

Breslin, S., (2009), State-led Development in Historical Perspective: From Friedrich List to a Chinese Mode of Governance, The University of Warwick, UK

Chia, S.Y., (2004), Economic Co-operation and Integration in East Asia, Asia-Pacific Review, Vol. 11, No. 1, May 2004, pp. 1-19.

Cherry, K. (2013). Sensation and Perception. New York: SAGE.

Collins, A., (2008), A People-Oriented ASEAN: A Door Ajar or Closed for Civil Society Organisation Contemporary Southeast Asia, Vol. 30 No. 2, August, pp 313-331.

Cuyvers, L., (2002), Contrasting the European Union and ASEAN Integration and Solidarity, Paper presented at the Forum EU-ASEAN Think Tank Dialogue "EU and ASEAN - Integration and Solidarity", 25-26 November 2002, Brussels.

Free Online Dictionary, (2013). Retrieved from Free Online Dictionary website: http://www.freeonlinedictionary.com

Jones, L., (2015), Explaining the Failure of the ASEAN Economic Community: The Primacy of Domestic Political Economy, The Pacific Review, Routledge, Taylor\& Francis Group.

Kamal, A., (2009), Progress of the Implementation of ASEAN Community in the ASEAN Region. ASEAN Secretariat, 16 - 19 June 2009

Kusalasari, M. A., (2011), Moving from State-Centered to People-Centered Security in ASEAN, Jakarta Post, July 19, 2011, p.7.

Lenz, T., 2011, Spurred Emulation: The EU and Regional Integration in Mercosur and SADC. European Studies Association Conference, Boston, March 3-5, 2011

Mochtan, A.K.P. (2012), ASEAN's internal issues are paramount, Jakarta Post, 23 August. p.5.

Moorthy, R., \& Benny, G., Is an "ASEAN Community” Achievable? A Public Perception Analysis in Indonesia, Malaysia, and Singapore on the Perceived Obstacles to Regional Community, University of California Press, pp. 1043-1066, November/December 2012

Morada, n. M., (2008), ASEAN at 40: Prospects for Community Building in Southeast Asia, Asia-Pacific Review, Vol. 15, Issue 1, pp. 36-55

Severino, R. C., (2006), Southeast Asia in search of an ASEAN Community: Insights from the former ASEAN Secretary-General,Singapore:Institute of Southeast Asian Studies

Sutherland, C. (2005), Another Nation-Building Bloc? Integrating Nationalist Ideology into the EU and ASEAN, Asia Europe Journal, No.3, pp 141-157) 
Termsak, C. (2009) 'In Defence of the ASEAN Charter' in T Koh, RG Manalo and W Woon (eds) The Making of the ASEAN Charter (Singapore: World Scientific), p.117-136.

Thompsons, E.C, \& Chulanee Thianthai., (2007). Attitudes and Awareness towards ASEAN: Findings of aTen Nation Survey. Singapore: ISEAS Publishing.

Troscianko, T., \& Smith, A. D., (2010), Perception. United Kingdoms: SAGE. 